\title{
Human-Computer Interaction Gearing Up for Work
}

\author{
Elspeth McKay, Trang Thomas, and Jenny Martin \\ RMIT University, Melbourne, Australia
}

\author{
elspeth.mckay@rmit.edu.au trang.thomas@rmit.edu.au \\ jenny.martin@rmit.edu.au
}

\begin{abstract}
Looking for work is complex. It involves a synthesis of decisions relating to many separate jobseeking tasks, requiring discrimination of how an individual's skills match the job description, whether the salary offered is acceptable, location of the work and the logistics of arranging suitable transport. These job-seeking tasks are even more difficult for the disabled, and despite the Web Access Initiative (WAI), there are no Web-enabled work searching systems designed as vocational rehabilitation tools. An opportunity exists among the educational technologists to devise a customizable learning platform that can supply a much needed life-long learning resource. It is becoming increasingly obvious that a range of computer supported collaborative learning (CSCL) systems may provide a ubiquitous approach to fulfilling the desire for reskilling the general population. This paper describes a research project in progress, designed to provide an interactive Web-enabled work searching resource for those undergoing vocational rehabilitation.
\end{abstract}

Keywords: system design, instructional design, project management, vocational rehabilitation, accessibility to information, lessons learned, Web-Portal development, human-computer interaction, computer supported collaborative learning

\section{Introduction}

This project aims to capture the efficiencies of human-computer interaction (HCI) to enhance jobsearching outcomes for people undergoing vocational rehabilitation programmes. Web-based employment service provision can provide open, flexible and distributed access for people who may experience difficulty in returning to work after a long absence. The environmental context of this research is unique, because it addresses the needs of people who suffer negative cognitive effects from long-term unemployment.

The main objective of this project is to provide a context for collaborative educational research that involves corporate/ academia/government sector partnerships. This project is designed to build a user friendly Web-Portal that brings together understanding employers, offering appropriate job opportunities, with unemployed people who require assistance in finding work. Custom designed, this new system will reflect real world issues faced by specialized placement agencies and their clients alike. Finding employers who are willing to become involved in a work place rehabilitation programme is a sensitive issue and will require much patience. Consequently the

Material published as part of this journal, either on-line or in print, is copyrighted by Informing Science. Permission to make digital or paper copy of part or all of these works for personal or classroom use is granted without fee provided that the copies are not made or distributed for profit or commercial advantage AND that copies 1) bear this notice in full and 2) give the full citation on the first page. It is permissible to abstract these works so long as credit is given. To copy in all other cases or to republish or to post on a server or to redistribute to lists requires specific permission from the publisher at Publisher@InformingScience.org specifications for this project take a simple approach in order to remain manageable.

The discussion in this paper will first identify the actual research question. The strength of the research team will be identified to convey the multidisciplinary theoretical framework 
that supports this innovative project. The project objectives are outlined, followed by the project methodology and research plan. It will be revealed that the system development phase did not run smoothly. Valuable lessons learned are noted for future research projects that involve building a system prototype. Summarized conclusions will draw this paper to a close, with suggestions for further research.

\section{Research Question}

It is all very well to devise an innovative learning system; complete with all the multimedia bells and whistles, however, the research team is cognizant of the need to allow for the pebble-in-thepond phenomenon, where the central reason for creating a specialized Web-Portal needs to be examined (Merrill, 2002). Much work is needed before the courseware design process can commence (Merrill, 2001).

The major research question to be examined by this project is:

\section{What is the most effective use of ICT in a Web-Portal that implements a work searching system for the long-term unemployed?}

\section{Researchers' Record}

Online Web-mediated instruction has emerged as an effective tool in bringing about a knowledge-sharing culture, which links the professional practice and education sectors (Driscoll, Bucceri, Reed \& Finn, 2001). The challenge of HCI has forced us to think of new ways to understand the social, historical and contextual nature of learning (Moreno, 2001), representing an interdisciplined knowledge synthesis. HCI comprises elements of computer science, cognitive psychology, social and organization psychology, ergonomics, human factors, artificial intelligence, linguistics, philosophy, sociology, anthropology, engineering and design (Preece, 1994). This research proposal clearly sits within the HCI domain and incorporates many of these necessary elements.

Overall this project takes a solution based approach drawing on information communications technologies (ICT) through a carefully designed HCI framework whereby appropriate use of technology will provide an informational leverage for those people in the community most often left behind. The collective strength of the research team provides a synthesis of special skills and knowledge to provide an interesting mix of theoretical perspectives needed to design a customized work-searching tool.

The Web-Portal development team consists of three across faculty academics from: Business, Applied Science and Constructed Environment. This is a complimentary collaborative research team bringing together distinctly different University entities: Psychology and Disability Studies, Business Information Technology, and Social Science. The team has been scoping the research domain since November 2001 (McKay \& Martin, 2002).

This project extends earlier work where a Telstra funded research project explored new usage of communications technologies to assist isolated, visually impaired older people (Thomas \& Urbano, 1993). A unique set of HCI skills is brought into this project team through an excellent track record as an early career researcher with first hand knowledge of the corporate sector and experience in systems design (McKay, 2003). The third researcher has an extensive background and expertise in the field of community mental health services (Martin, 2003) and will be utilized to locate potential employers and support services to be included in this innovative Web-Portal. 


\section{Project Objectives}

Enhanced job-seeking resources will benefit many people ordinarily not included in mainstream programmes (Kakutani, 1998). In Australia there are currently 19\% of the unemployed jobseekers who through their disability may be disadvantaged in accessing information for gaining employment. This project will identify some of the challenges involved in turning this inequity around. The research team believes a good place to begin is to investigate the effectiveness of including a type of e-Learning system, customized to meet the special needs of vocational rehabilitation. Computers can offer flexible and dynamic instructional/learning environments. They can depict minute detail or convey holistic environments where imaginary events can be witnessed (Gibbons \& Fairweather, 1998). However due to the sensitivity of this innovative customized computer-mediated job-seeking tool (to provide a non-threatening and cognitively safe environment), the research methodology requires careful attention.

The Web-Portal will comply with current World Wide Web Consortium (W3C) accessibility guidelines. The content for this system will involve various ICTs to deliver seven separate modules relating to: (1) employers willing to participate in vocational rehabilitation programmes, (2) job vacancies, (3) planning for a day at work (food, clothes, social interaction, travel), (4) examples of current working environments, (5) the interview process, (6) what to do when they choose someone else, and (7) alternative ways of gaining work experience.

The project outcomes can be described in both short and longer terms. In the short term, the deliverables will include:

- A prototype model that will be integral and strengthen the knowledge management issues related to providing specialist computerized vocational rehabilitation/training programmes

- An effective Web-Portal that includes comprehensive opportunities for learning, retraining in professional practice

- A new and appropriate approach to specially targeted work search resources

While in the longer-term this project has to potential to advise on:

- Sound strategies for maximizing the relationship between business and government interaction, in relation to provision of employment services to people with a disability

- A list of key issues, which influence the service providers in relation to dealing with government agencies, and intellectual disability/mental health self-help bodies

\section{Project Methodology and Research Plan}

There can be no doubt that Web-Portal development is fraught with many traps. None the least associated with the notion of having to work at a warp speed (Flicker, 2002) to deliver products on target, on time and on budget. Much is known about systems design and development. In so far as the physical Portal development, the methodology for this project will be rather straightforward. The researchers have adopted a standard systems approach (McLeod, 1993); initiating an overview of the problem area (that certain people need assistance in looking for work). They have recognized the complexity of the environmental system (stakeholders identified to include vocational rehabilitation experts, employment facilitators, long-term unemployed, computer systems designers, multimedia experts, etc). After completing the system overview, the researchers will have to identify the sequence of sub-systems that may need to arise. Once the blueprint is in 
place, this conceptual schema will be analysed to ensure correct placement of each system choice sub-level. Finally there will be a comprehensive evaluation of the chosen solutions to seek out alternatives not recognized in the initial schema development.

Therefore the methodology required for this research project will need to cope with a range of seemingly disparate elements. For instance: the learning/training content, the expected user profile, maximization of the HCI aspects (database and communications technologies), and correctly identifying the research variables to facilitate the product evaluation process.

\section{Project Approach}

The researchers will investigate a number of issues in relation to the effectiveness of available software tools and associated hardware to lessen the possibility of computerphobia (Fisher, 1991). However, the overarching investigation will be to determine:

How best to represent the employment possibilities in a Web-based work searching system?

Keeping in mind the special nature of the intended users, decisions will be made relating to the look and feel of the Portal to minimize stress and maximize enjoyment.

\section{Project Methodology}

It is expected that identifying the appropriate learning/training content will be an ongoing process. Web-based training combines three socio-technical developments: distance learning, computer-conveyed education, and Internet technologies (Horton, 2000). As far as the expected profile of the Web-Portal users, it will be assumed that the users will be people from a wide range of community based vocational rehabilitation services. However, they may possess a commonality of long-term unemployment.

Database management techniques will enable the researchers to maximize the HCI aspects of the Portal design, forming the largest component of the initial system development. While the communications technologies form a more advanced aspect of this research project.

The project will be conducted utilizing a six-phase project methodology:

\section{Concept development: Phase-1}

There is an emerging international trend for researchers to focus on workforce accessibility (Section 508, 2001). There are many types of human functional disability - some of which are the result of the aging process (Vanderheiden, 1990). However; most of this research concentrates on catering for the more definable functional limitations of work seekers, with only limited research specifically designed to assist those recovering from a severe medical condition that hinders concentration and motivation (Alexander, 1991). A limited number of researchers have been aware of the need to investigate alternative ways to assist the learning/processes involved in reskilling the long-term unemployed (McKay \& Martin, 2002). The authors believe that $19 \%$ of Australia's unemployed are potentially disadvantaged in accessing information due to their disability. According to special needs educators (Langone, Clees, Reiber \& Matzko, 2003), touch screens simplify accessibility to computerised information. Furthermore the industry sector providing such assistive technologies concludes that screen navigation is far easier for people who cannot understand the concept of using computer keyboards. As a result, the development and evaluation of a customized work search system for vocational rehabilitation is timely. 


\section{Scoping: Phase-2}

Given the potential for significant scope creep, this project has been limited to building a standalone pc-based prototype system, with limited user testing and analysis. The key elements include:

- a user needs' analysis

- selection of appropriate instructional strategies

- design and development of a functional prototype system

- a limited user trial

- design of research interview questions

- development of the cognitive/performance ability scale (McKay, 2000)

\section{Preliminary design: Phase-3}

The first stage was to devise the system specifications. In the longer-term, the system will comprise a fully integrated Web-based Portal that contains links to databases containing employer details. However for this initial research project, a functional prototype system will be built (containing basic system requirements without the complication of Web technologies and a multi-user environment).

Unfortunately, many graphical user interfaces (GUIs) that promote visual enhancements to otherwise textual displays are often boring (Landa, 2001), and lack inspiration; consequently they do not promote self-confidence. The system prototype will need to range in sophistication, ensuring that at the top end of the system's tools, it will provide examples of an individual's working day. This will be achieved with video clips on demand (VOD) (Okamoto, Matsui, Inoue \& Cristea, 2000). VODs are an excellent medium for providing simulations to demonstrate the process of getting ready, preparing lunch etc at home, and a number of different example work-place settings. Visual examples such as these will enable an experiential tour-like environment. Moreover these VODs will be designed to enrich a person who may have no prior working experience.

Although the standalone pc-based system will be highly visual in terms of providing employment location advice with voice descriptions to enhance the VODs implemented as scaffolding (Peal \& Wilson, 2001): 150 elements, (to segment work-related tasks), there will be a range of other screen display techniques installed such as text and simple pictorial objects. These pictorial objects will also be enhanced to provide a rotating $360^{\circ}$ view of working environments.

People construct knowledge about the working world through experiential processing; organizing these experiences into knowledge structures, and what is believed about those experiences (Jonassen, Meyers \& McKillop, 1996). In order to provide information about work-place environments in a non-threatening manner, the researchers have utilized educational technology strategies to implement seamless links between the Web-based communications and the system prototype (Rosenberg, 2001). Therefore an important educative feature of the standalone prototype system is to create the relationship between the (re)-learning of basic work-skills (listening and following instructions), work-communities (social interaction and where to go for more information in the work-place), and work-performance expectations (competency based training). It is anticipated that the simulated work-placement VOD vignettes will work well (Pappo, 2001). This is because the (soft) skills to be conveyed are subtle, and the knowledge associated with them is complex. Many of the vignettes will involve people interacting with other people (like effective listening strategies and simple recall tasks). Simulations work best when the greatest challenge is 
not acquiring factual knowledge but applying knowledge skills, and beliefs in complex, unique situations (Horton, 2000, p.569).

Ordinarily, people approach their learning in many different modes; some prefer to receive textbased material without pictorial content, while others need to have the opportunity of receiving both (McKay, 2000). The tendency to rely solely on the graphical image to convey meaning could prove to be a mistake with a computerized system, as many people require training to read visual messages (McNamara, 1988).

From the outset the system is designed for easy use (see Figure 1). Where possible, operation will be through touch screen technology, to reduce the common and understandable apprehension towards using a computer. This apprehension is called computerphobia by Fisher (1991). To ensure that users of the system are not stressed by lack of computer (keyboard and mouse) skills, the prototype primarily functions using a database already loaded with employment prospects. Moreover, the touch screen interfaces will link work place concepts, with the employer database, for locations, positions available, pay-rates etc.

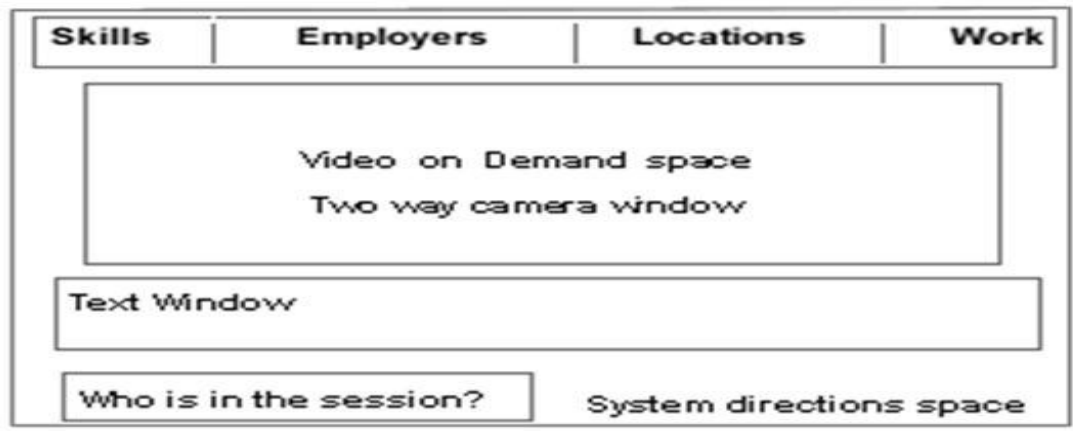

Figure 1: System Prototype Framework

Once the prototype is completed, the next stage of the project will be to test and calibrate an assessment instrument, to test for usability of the system. A representative sample of participants will be required for this calibration exercise. This means a convenience sample of people will be required to test the prototype system, including a post work search interview and assessment/feedback sessions. This calibration technique is to maintain the validity of the testing instrumentation. Any weaknesses in the assessment items can be identified during this process. For instance: wrongly worded questions. Alterations can then be made to correct any problems identified.

\section{System development: Phase-4}

On the surface the research team originally expected that the building of a system prototype would be straightforward. What transpired was far from expectations. A consultant system developer was engaged to build the initial prototype. The design specifications were completed by the research team. A prototype system was developed using the most appropriate multimedia development tools. A decision was made not to utilize local software specialists for customized/home grown products (built in-house). Instead, an industry standard was used utilizing the comprehensive range of Macromedia, Inc.'s products such as Studio MX. The prototype's database was generated through MS Access. The database reports or job listings output to an XML file for the 
prototype screen display created as a Flash MX movie page. This functionality should have been relatively easy to achieve.

Unforeseen problems developed during the early stages of the prototype building exercise. These problems were largely due to the fluid nature of the design methodology adopted by the consultant builder. In hindsight, too much time was taken up reviewing a system persona. The intention was to characterize a typical user. The persona should have isolated the research team from making personal judgments relating to the system specifications.

Instead, excessive time was spent in meetings with the consultant devising a comprehensive view of the typical user. Consequently, the writing of the system specifications took on a fine-grained approach that was not appropriate for the temporary nature of the prototype system. Notwithstanding this mistake, a comprehensive Menu Hierarchy/Functionality Table was developed to identify the various levels of user options to be adopted by the system. Unfortunately, when it came time to populate the prototype and seed the database with specific content (text displays, graphical metaphors, video clips, employer details, and sample job vacancies); the system builder was unwilling to carryout this process. Responsibility for creating the electronic content resources then fell upon the research team.

Following a series of delayed acceptance testing sessions where defective modules and resources were identified and rebuilt, the research team is now confident that the prototype satisfies the initial requirements. It is anticipated that the prototype will be completed early 2004, with the required interactive employer database, complete with the VODs that were originally planned.

\section{Execution phase and lessons learned: Phase-5}

A pilot study was executed over a four-month period. The project did not require a sample group of users, as this is to be the focus of the research team's next research project. Arrangements were made with appropriate people, already known to the team, to test the system during 2003, when components were progressively finished. Preliminary feedback, including that of several noncomputer users, was very positive. The users found the system easy to use, informative, and could relate to the characters in the various video vignettes.

It was hoped that the first two months of the pilot would see the prototype placed on site at one of the projects' sponsors. Due to the slowness of the prototype system development this was not possible. Furthermore, initial user testing still needs to be conducted during 2004. Valuable lessons have been learned that relate to working with consultants brought in for a funded academic research project. Above all it should be ascertained very early (perhaps during the drawing up of a Contract or Legal Agreement), that all parties understand the scope of their commitment.

Once a sponsor for the final system building exercise is found, the prototype system will be available for use by a small select group of users. After each session on the system, the user will be interviewed by a trained community centre facilitator known to the user, using the specially prepared research Questionnaire. It is anticipated that by following this process, the user will not be stressed by new people external to their familiar surroundings, and furthermore, their privacy will be maintained. The research team will only receive the data. The cognitive performance data will then be analysed using the QUEST interactive test-analysis system (Adams \& Khoo, 1996).

\section{Closure: Phase-6}

A Closure Report will analyse the pilot study results, and evaluate whether the initial project objectives/deliverables have been achieved, within time and budget. The lessons learned log will also be included for improving the ongoing development of a full (Web-enabled) work searching system, as part of another research project. 


\section{Summary}

This paper has described a research project in progress. Despite the acknowledgement by professionals in the field that job-seeking tasks are even more difficult for the disabled, and even though the WAI is making some progress to bring forth solutions, at this point in time, there are no Webenabled work searching systems designed as vocational rehabilitation tools. CSCL research often targets the more ubiquitous systems designed for reskilling the general population.

The discussion gave an overview of the context upon which this project has developed. Of prime importance is the research question that drives the project as a whole. Nothing is known about the best methods to provide work-searching resources for vocational rehabilitation, and even less is in place to provide any leadership. The researchers can be identified as dynamic in their chosen fields with experience that equips them well for this innovative socio-technological problem.

The project's main objective is to pave the way for further work that is much needed in the area of specialized learning/training systems' design.

Surely the education/training sectors do have a meaningful contribution to make here. Generic CSCLs are not the answer. If this project does nothing more than initiate more solutions engineering of this type from other systems' designers, then we are half way there.

\section{References}

Adams, R. J. \& Khoo, S.-T. (1996). Quest:The interactive test analysis system. Melbourne: Australian Council for Educational Research.

Alexander, K. (1991). Understanding and coping with schizophrenia. Melbourne: Schwartz \& Wilkinson.

Driscoll, J.-A., Bucceri, M., Reed, A. \& Finn, A. (2001). Fast path to success with Centra: Best practices, tips and techniques in live e-learning. MA: Centura Software.

Fisher, M. (1991). Computerphobia in adult learners. Computer Education, 14-19.

Flicker, B. (2002). Working at warp speed: The new rules for project success in a sped-up world. San Francisco: Berrett-Koehler.

Gibbons, A. \& Fairweather, P. (1998). Computer-based instruction: Design and development. New Jersey: Educational Technology Publications.

Horton, W. (2000). Designing web-based training. New York: Wiley.

Jonassen, D. H., Meyers, J. M. \& McKillop, A. M. (1996). From constructivism to constructionism: Learning with hypermedia/multimedia rather than from it. In B. G. Wilson, Constructivist learning environments: Case studies in instructional design (pp. 93-106). New Jersey: Educational Technology Publications.

Kakutani, K. (1998). New life espresso: Report on a business run by people with psychiatric disabilities. Psychiatric Rehabilitation Journal. 22 (3, Fall).

Landa, R. (2001). Graphic design solutions. Stamford: Thomson Learning.

Langone, J., Clees, T. J., Reiber, L. \& Matzko, M. (2003). The future of computer-based interactive technology for teaching individuals with moderate to severe disabilities: Issues relating to research and practice, Retrieved Jan 2, 2004 from Http://Jset.Unlv.Edu/18.1t/Langonet/First.Html

Martin, J. (2003). Historical development of critical social work practice. In J. Allan, B. Pease \& L. Briskman, Critical social work: Theory and practice: An introduction to theories and practices (pp. 17-32). NSW: Allen and Unwin.

McKay, E. (2000). Measurement of cognitive performance in computer programming concept acquisition: Interactive effects of visual metaphors and the cognitive style construct. Journal of Applied Measurement, 1 (3), 257-286. 
McKay, E. (2003). Automated educational/academic skills evaluation: Enhanced opportunities for young people returning to study or vocational training. Funded research project by the Telematics Course Development Fund. Melbourne.

McKay, E. \& Martin, J. (2002). Web-work-search system: An enhanced accessibility. In S. McNamara \& E. Stacey (Eds.), Australian society for educational technology international education \& technology conference (ASET 2002): Untangling the web-establishing learning links, July 7 - 10, 2002, Melbourne, Australia, CD ISBN: 00958126100.

McLeod, R. (1993). Management information systems: A study of computer-based information systems. New York/Toronto: Macmillan.

McNamara, S. E. (1988). Designing visual analysis training for the individual learner: An examination of individual learner differences and training content and procedures. Faculty of Education. Melbourne, Monash University: 543.

Merrill, M. D. (2001). First principles of instruction. Retrieved Jan 02, 2004 from http://www.id2.usu.edu/Papers/5FirstPrinciples.PDFUtah

Merrill, M. D. (2002). Pebble-in-the-pond model for instructional development. Performance Measurement, 41 (7), 41-44. Retrieved $21^{\text {st }}$ August 2003 from http://www.ispi.org/pdf/Merrill.pdf

Moreno, R. (2001). Contributions to learning in an agent-based multimedia environment: A methods-media distinction. In T.Okamoto, R.Hartley, Kinshuk \& J.P.Klus (Eds.), IEEE international conference on advanced learning technologies (ICALT 2001): Issues, achievements, and challenges (pp. 464-465). Madison: IEEE Computer Society, LTTF:IEEE.

Okamoto, T., Matsui, T., Inoue, H. \& Cristea, A. (2000). A distance-education self-learning support system based on a VOD server. In Kinshuk, C. Jesshope \& T. Okamoto (Eds.), International Workshop on Advanced Learning Technologies (IWALT 2000): Advanced Learning Technology: Design and Development Issues (pp. 71-72.), Palmerston North: IEEE Computer Society.

Pappo, H. A. (2001). Simulations for web-based training. In B. H. Khan, Web-based training (pp. 225228). New Jersey: Educational Technology Publications.

Peal, D. and Wilson, B. (2001). Activity theory and web-based training. . In B. H. Khan, Web-based training (pp. 147-153). New Jersey: Educational Technology Publications.

Preece, J. (1994). Human-computer interaction. Harlow: Addison-Wesley.

Rosenberg, M. J. (2001). E-Learning: Strategies for delivering knowledge in the digital age. New York: McGraw-Hill.

Section508. (2001) Workforce investment act of 1998, electronic and information technology: Retrieved Feb $8^{\text {th }}, 2004$ from http://www.usdoj.gov/crt/508/508law.html

Thomas, T. \& Urbano, J. (1993). Telelink and the visually-impaired elderly: A group dynamic analysis. Australian Journal on Ageing, 12 (1), 25-29.

Thomas, T. \& Urbano, J. (1993). Telephone group support program for the elderly. Clinical Gerontolgist. $13(2), 61-71$.

Vanderheiden, G. C. (1990) Thirty-something (million): Should they be exceptions? Trace.wisc.edu. Retrieved Feb 10 $0^{\text {th }}, 2004$ from http://trace.wisc.edu/docs/30_some.htm

\section{Biographies}

Elspeth McKay has successfully carried her doctoral findings through to the design and development of two interactive e-Learning systems (2003 Telematics Trust Fund Grant - Automated Educational /Academic Skills Evaluation: Enhanced opportunities for your people returning to study or vocational training, and 2003 RMIT Virtual Research Institutes Small Grants Scheme Work Finder Pilot Project: Enhanced Job Seeking Tools - Vocational Rehabilitation), which enhance opportunities for the special requirements of vocational rehabilitation for disabled members 
of the community. Her work on cognitive performance measurement for assessing readiness for returning to study/retraining breaks new ground, utilizing multimedia with special stress reducing strategies. Moreover her enthusiasm for innovation can also be seen in her readiness to invoke Touch Screen technologies into her projects that initiate access to information technology.

Professor Trang Thomas has carried out research has carried out research in the field of psychology and disability studies for 16 years. Her research focuses on the welfare of people with special needs, such as, the elderly, the migrants and those of non-English speaking backgrounds, as well as the use of new technologies to assist people with disabilities. She was Chief Investigator and recipient of several major competitive research grants, including: ARC, NHMRC,

RADGAC, Bureau of Immigration Research, Vic Health Promotion Foundation, as well as research grants from government and industry including Telstra Program funding, DEET Access and Equity Research Grants. As former Director of the Centre for Applied Social Research, Professor Thomas has significant experience in conducting applied research, having written over 100 research articles and conference papers.

Dr Jenny Martin has both practical and academic experience in the field of mental health. She was a founding member of the North West Community Assessment Treatment Team as well as having worked in psychiatric in-patient and community mental health settings as a senior clinician. She was appointed to the Professorial Unit, at the now closed, Larundel Psychiatric Hospital. Dr Martin's Master's thesis was in the field of mental health, with a comparative study of community and psychiatric hospital treatments. In 1998 she was commissioned by the Victorian Institute of Forensic Mental Health to prepare an Issues Paper on the acute mental health needs of women prisoners. This involved the design and execution of an extensive consultation with both women prisoners and service providers. Many of these services are relevant to the current study. For instance, mental health services and the psychiatric disability support services under the umbrella of VICSERV. Dr Martin has coordinated Mental Health, a course offered across RMIT University located in the School of Social Science and Planning, for the past five years. She has published and presented conference papers in the areas of women and mental health, forensic mental health and transcultural mental health, as well as conducting radio interviews on mental health and community care. 